\title{
Factors associated with use of malaria control interventions by pregnant women in Buwunga subcounty, Bugiri District
}

\author{
Elizabeth Muhumuza ${ }^{1}$, Noel Namuhani ${ }^{1 *}$, Bonny Enock Balugaba ${ }^{1}$, Jessica Namata ${ }^{1}$ \\ and Elizabeth Ekirapa Kiracho ${ }^{2}$
}

\begin{abstract}
Background: In Uganda, the Government has promoted the use of intermittent preventive treatment of malaria in pregnancy (IPTp) and insecticide-treated bed nets (ITNs) as malaria control strategies for pregnant women. However, their utilization among pregnant women is low. This study aimed at assessing factors associated with use of IPTp for malaria and ITNs by pregnant women in Buwunga sub-county, Bugiri District.
\end{abstract}

Methods: This was a cross-sectional study, conducted in Buwunga sub-county, Bugiri District, employing quantitative data collection tools. A total of 350 household members were randomly selected to participate in the study. Data were entered and analysed using Epi info version 3.5.1; bivariable and multivariable analysis was done to assess the factors associated with use of IPTP and ITNs among pregnant women.

Results: The level of uptake of IPTp1 (at least one dose) was $63.7 \%$ while IPTp2 (at least two doses) was $42.0 \%$. More than half (58.6\%) of the mothers had slept under an ITN the night before the survey. Slightly more than half (51.9\%) of the mothers mentioned stock outs as the major reason for not accessing IPTp and ITNs. The main factors that were statistically significant for IPTp2 uptake were the knowledge of mothers on IPTp2 (AOR $2.4895 \% \mathrm{Cl} 1.53-4.02$ ) and providing women with free clean water at the antenatal care (ANC) clinic (AOR $3.6395 \% \mathrm{Cl}$ 2.06-6.39). Factors that were significant for ITN utilization included education level of mothers (AOR $2.0395 \% \mathrm{Cl}$ 1.09-3.78), ease of access (AOR $2.7495 \% \mathrm{Cl}$ 1.65-4.52), and parity (AOR $1.7195 \% \mathrm{Cl} 1.01-1.29$ ).

Conclusion: The level of uptake of the two recommended doses of sulfadoxine-pyrimethamine (SP) tablets for malaria prevention (IPTp2) was low, slightly more than half of the mothers slept under an ITN the night before the survey. Appropriate measures to increase the level of uptake of IPTp2 and coverage of ITNs among pregnant women should be implemented, and these include providing health education about IPTp and ITNs, and ensuring that mothers are provided with free safe clean water at ANC clinic.

Keywords: ITN use, IPTp2 uptake, Malaria control interventions, Pregnant women

\section{Background}

Malaria kills over a million people each year and causes 300-500 million clinical cases worldwide, with $80 \%$ of the deaths and $91 \%$ of the clinical cases occurring in sub-Saharan Africa [1]. More than half of the world's

\footnotetext{
*Correspondence: noelnamuhani@gmail.com

1 School of Public Health, College of Health sciences, Makerere University, P.O. Box 7072, Kampala, Uganda

Full list of author information is available at the end of the article
}

population is at risk of contracting malaria [2]. Malaria disproportionately affects children and pregnant women, especially in resource-limited, developing countries [2]. During pregnancy, malaria may lead to several complications that include premature delivery or low birth weight, cerebral malaria with abnormal behaviour, impairment of consciousness, seizures, coma, or other neurological abnormalities [3].

The World Health Organization (WHO) recommends a package of intermittent preventive treatment in 
pregnancy (IPTp) with sulfadoxine-pyrimethamine (SP) and use of insecticide-treated bed nets (ITNs), together with effective case management of clinical malaria and anaemia in malaria-endemic areas, such as Africa $[4,5]$. IPTp consists of two doses of SP taken one month apart commencing in the second trimester. With collaboration from malaria and reproductive health programmes in Uganda, both IPTp and ITNs are usually availed at the ANC clinics [6]. By 2010, the Roll back malaria partnership had aimed at ensuring that all pregnant women receive at least two doses of IPTp and $80.0 \%$ of people at risk of suffering from malaria sleep under ITNs [7]. However the coverage of these preventive interventions among pregnant women remains low for many countries in sub-Saharan Africa [8]. The mean coverage of two doses of SP is $24.5 \%$ despite having over $80 \%$ of the women attending at least two ANC visits according to a survey in 27 countries [7]. This is an indication of substantial missed opportunities at the ANC clinics [6]. The same survey indicated that only $35.3 \%$ of pregnant women slept under ITNs.

According to the 2009 Uganda Malaria Indicator Survey, $44 \%$ of pregnant women had slept under an ITN the night before the survey and $32 \%$ received two doses of IPTp [9]. This fell short of the Ministry of Health target of increasing IPTp2 (at least two doses) uptake to $80 \%$ (Health Sector Strategic Plan II). The situation is worse in Bugiri District. According to Bugiri District STRIDES Baseline Needs Assessment, only $30.2 \%$ of the pregnant women acquired more than one dose of IPTp and only $40 \%$ slept under an ITN. This low coverage is said to have escalated the level of malaria morbidity and mortality among pregnant women and children under the age of 5 years.

High access and utilization of IPTp and ITNs by pregnant women is necessary to reduce the burden of malaria among pregnant women. The study examined the factors associated with the use of these malaria control interventions by pregnant women in Buwunga sub-county, Bugiri District.

\section{Methods}

\section{Study design and setting}

This was a community-based, cross-sectional, household study that utilized quantitative data collection tools. The study was conducted in Buwunga sub-county, Bugiri District, which is located in southeastern Uganda. The District borders Tororo to the northeast, Iganga to the west, Namutumba to the northwest, Mayuge to the southwest, and Namayingo to the east. It is $178 \mathrm{~km}$ from the capital city of Kampala. The district has a population of 390,076 [10]. Buwunga sub-county is located in the northwestern part of Bugiri District with a population of 46,979 [10].
It has four parishes and 28 villages. Buwunga has one health centre III and three health centre II. The study population comprised all pregnant women in the study area, as well as women who had given birth 12 months prior to the study.

\section{Sample size determination and sampling}

A sample size of 350 households was determined using the Kish Lisle formula of 1965 . The calculation was based on a $95 \%$ confidence interval, a $35 \%$ estimated proportion of mothers who use malaria control interventions in Bugiri District [9], a sampling error of $5 \%$ and a nonresponse rate of $10 \%$. Multistage sampling was used. The stages involved simple random sampling of three parishes out of the four parishes in the Sub-county, followed by the selection of four villages out of the six to eight villages per selected parish. The random selection of the parishes and the villages involved use of the ballot method. Lastly, 29 households were randomly sampled from each of the 12 villages. Village health team members (VHTs) and local leaders helped in locating homes with eligible respondents. A list of all eligible households in each village was obtained, and then systematic random sampling was used to obtain the 29 households from each village. The sampling interval depended on the number of eligible households in each village.

\section{Data collection and analysis}

Semi-structured questionnaires were used to collect information on IPTp2 uptake and utilization of ITNs, women's sociodemographic factors, women's knowledge and attitudes towards ITNs and ITPp, and health system factors. The tools were pre-tested and corrected on the basis of the findings to ensure that they were accurate and comprehensive. Data was collected during a dry season in the month of September, 2014. Quantitative data were entered and analysed using EPI INFO Version 3.5.1 computer software. Descriptive statistics, such as frequencies and proportions, were used to describe the study subjects. Bivariable analysis and multivariable analysis was done to obtain odds ratios and adjusted odds ratios, respectively, at $95 \%$ confidence intervals to determine the factors associated with use of ITNs and IPTp2. Variables that were statistically significant at bivariable analysis $(\mathrm{P}=<0.05)$ were considered for multivariable analysis.

\section{Results}

\section{Sociodemographic characteristics of the respondents}

The majority $(61.7 \%)$ of the women were more than 30 years of age, $17.4 \%$ were teenagers. The mean age of the respondents was 26.2 years. Most $(80.9 \%)$ of the women had attained at most primary education. Some (58.0 \%) were Muslims, and $25.4 \%$ were Anglicans 
(25.4\%). Some $86.9 \%$ were married; $85.4 \%$ of the women were farmers. More than half (52.6\%) of the women had had four or more pregnancies (Table 1 ).

\section{Uptake of IPTp at ANC clinics}

The level of uptake of IPTp1 (at least one dose) was $63.7 \%$ while IPTp2 was $42.0 \%$. Most respondents (63.1\%) first attended ANC clinic in their second trimester of pregnancy while $10.9 \%$ first attended ANC clinic in their final trimester.

\section{Utilization of ITNs}

More than half (58.6\%) of the mothers had slept under an ITN the night before the survey; $82.9 \%$ of the

Table 1 Sociodemographic characteristics of the mothers

\begin{tabular}{|c|c|c|}
\hline Variable & Frequency $(n=350)$ & Percentage (\%) \\
\hline \multicolumn{3}{|l|}{ Age (years) } \\
\hline$<20$ & 61 & 17.4 \\
\hline $20-30$ & 73 & 20.9 \\
\hline$>30$ & 216 & 61.7 \\
\hline \multicolumn{3}{|c|}{ Highest level of education } \\
\hline None & 51 & 14.6 \\
\hline Primary & 232 & 66.3 \\
\hline Secondary & 65 & 18.6 \\
\hline Tertiary & 2 & 0.6 \\
\hline \multicolumn{3}{|l|}{ Religion } \\
\hline Anglican & 89 & 25.4 \\
\hline Catholics & 31 & 8.9 \\
\hline Moslem & 203 & 58.0 \\
\hline Others $^{a}$ & 27 & 7.7 \\
\hline \multicolumn{3}{|l|}{ Marital status } \\
\hline Married/cohabiting & 304 & 86.9 \\
\hline Separated & 14 & 4.0 \\
\hline Single & 30 & 8.6 \\
\hline Widowed & 2 & 0.6 \\
\hline \multicolumn{3}{|l|}{ Occupation } \\
\hline Farmer & 299 & 85.4 \\
\hline Not employed & 27 & 7.7 \\
\hline Others $^{b}$ & 24 & 6.9 \\
\hline \multicolumn{3}{|l|}{ Parity } \\
\hline One & 61 & 17.4 \\
\hline Two & 52 & 14.9 \\
\hline Three & 53 & 15.1 \\
\hline Four & 49 & 14.0 \\
\hline Five and above & 135 & 38.6 \\
\hline \multicolumn{3}{|l|}{ Number of co-wives } \\
\hline 0 & 222 & 63.4 \\
\hline 1 & 89 & 25.4 \\
\hline$>1$ & 39 & 11.2 \\
\hline
\end{tabular}

Others $^{\mathrm{a}}$ Born-again Christian, Seventh Day Adventist, Atheist Others ${ }^{\mathrm{b}}$ Civil servant, Business, Commercial motorcyclist respondents had used the net for at least 1 year. The health facility $(35.4 \%)$ and sub-county $(43.7 \%)$ headquarters were the main sources of the nets; 17.5 and $3.4 \%$ of the mothers obtained their ITNs from the market and non-governmental organizations (NGOs), respectively. The nets that were obtained from the health facility, subcounty headquarters, and NGOs were free of charge.

\section{Individual factors}

About half (53.1\%) of the mothers mentioned that they knew the purpose of IPTp tablets; $50.3 \%$ mentioned the correct use of IPTp tablets as a malaria preventive remedy. The majority $(88.6 \%)$ of the mothers believed that they were susceptible to malaria; $54.0 \%$ said that a mother had to take the tablets three or more times; $33.4 \%$ confessed having no idea of the number of times to take the SP tablets. Over $47 \%$ of the mothers did not know the effects of malaria on pregnant women; when asked about the effect of malaria on their unborn child, most mothers $(45.1 \%)$ did not know of any effect, and $39.4 \%$ mentioned abortion. The major source of knowledge about IPTp was from health workers (88.2\%), friends $(4.8 \%)$ and the media (4.8\%). Mothers who mentioned that SP tablets had to be taken at least twice and that the tablets are for malaria prevention during pregnancy were considered to be knowledgeable about the use of IPTp (Table 2).

\section{Healthcare system factors}

Most $(68.6 \%)$ of the mothers were served with free clean water at the ANC clinic to swallow the tablets; $88.0 \%$ said that health workers had a positive attitude towards pregnant women; $82.9 \%$ of the respondents spent more than $30 \mathrm{~min}$ at ANC clinic; $54.9 \%$ said that the ANC clinic was far away $(>5 \mathrm{~km})$ from their homes. The majority $(64.0 \%)$ of the women said that it was difficult to access ITNs; $81.7 \%$ said it was very easy to access IPTp tablets at ANC clinics. Some of the commonly cited reasons for not accessing ITNs and IPTp by pregnant mothers included shortage of tablets and ITNs (51.9 \%), long waiting time $(19.2 \%)$, and demand for money by health workers (14.2\%) (Table 2).

\section{Factors associated with use of IPTp2}

Being knowledgeable about the use of IPTp tablets (OR $2.75,95 \%$ CI 1.76-4.28), being in position to easily access IPTp tablets (OR 2.10, $95 \%$ CI 1.16-3.89), and being served with free clean water (OR 4.35, $95 \%$ CI 2.567.40), at the ANC clinic were factors that showed a statistically significant association with the uptake of IPTp2 at bivariable analysis level. Women who were knowledgeable about the use of IPTp were 2.75 times more likely to receive at least two doses of IPTp tablets compared to 
Table 2 Individual and healthcare system factors for use of IPTp and ITNs

\begin{tabular}{|c|c|c|}
\hline Variable & Frequency $(n=350)$ & Percentage (\%) \\
\hline \multicolumn{3}{|l|}{ Knows the use of IPTp } \\
\hline Yes & 186 & 53.1 \\
\hline \multicolumn{3}{|l|}{ Use of IPTp tablets $(n=186)$} \\
\hline Prevent malaria & 95 & 50.3 \\
\hline Promotes weight gain & 14 & 7.4 \\
\hline Gives a lot of blood & 42 & 22.2 \\
\hline $\begin{array}{l}\text { Makes the baby strong and } \\
\text { healthy }\end{array}$ & 23 & 13.8 \\
\hline Others & 12 & 6.3 \\
\hline \multicolumn{3}{|c|}{ Number of times a pregnant woman has to take IPTp tablets } \\
\hline Once & 13 & 3.7 \\
\hline At least twice & 220 & 62.9 \\
\hline Do not know & 117 & 33.4 \\
\hline \multicolumn{3}{|c|}{ Effects of malaria on pregnant women } \\
\hline Anaemia & 100 & 28.6 \\
\hline Death & 42 & 12.0 \\
\hline Do not know & 165 & 47.1 \\
\hline Nothing & 2 & 0.6 \\
\hline Others & 41 & 11.7 \\
\hline \multicolumn{3}{|l|}{ Effects of malaria on unborn baby } \\
\hline Abortion & 138 & 39.4 \\
\hline Intra-uterine death & 24 & 6.9 \\
\hline Low birth weight & 18 & 5.1 \\
\hline Do not know & 158 & 45.1 \\
\hline Others & 12 & 3.4 \\
\hline \multicolumn{3}{|c|}{ Reasons for not accessing ITNS/IPTp with ease $(n=239)$} \\
\hline Long waiting time & 46 & 19.2 \\
\hline $\begin{array}{l}\text { Nurses do not attend to } \\
\text { patients - better to do each } \\
\text { separately well }\end{array}$ & 22 & 9.2 \\
\hline Stock-outs of tablets and ITNs & 124 & 51.9 \\
\hline $\begin{array}{l}\text { Demand for money by health } \\
\text { workers }\end{array}$ & 34 & 14.2 \\
\hline Others & 13 & 5.4 \\
\hline
\end{tabular}

those women with less knowledge. Serving mothers with free clean water at ANC clinics increased the likelihood of mothers receiving at least two doses of IPTp tablets by 4.35 times (Table 3 ).

Variables that were statistically significant for use of malaria control interventions at bivariable analysis were considered for multivariable analysis. The logistic regression analysis revealed that being knowledgeable of IPTp use increased the likelihood of receiving at least two doses of IPTp tablets by 2.48 times, (AOR 2.48, 95 \% CI 1.53-4.02). Providing free clean water at ANC clinics increased the chances of women taking at least two doses of IPTp tablets by 3.63 times (AOR 3.63, 95 \% CI 2.06-6.39) (Table 3).
Women who had education level of primary and below had reduced chances of sleeping under a mosquito net (AOR 0.49, 95 \% CI 0.26-0.92). Women who had three to five pregnancies had increased chances of having slept under a net compared to women who had fewer than three and more than five pregnancies. Long distance to the health facility reduced chances of women sleeping under a net by $60 \%$ (Table 4). Multivariable analysis also revealed that education level, ease of access and parity remained significant for utilization of bed nets. Women who had attained an education level of secondary and above were two times more likely to sleep under ITNs compared to those with an education level below secondary (AOR 2.03, 95 \% CI 1.09-3.78) (Table 4).

\section{Discussion}

The WHO recommendations emphasize that pregnant women should receive at least two doses of SP during pregnancy. The $42.0 \%$ uptake of SP for IPTp2 in this study is lower than the targeted global coverage of $80 \%$ in 2010 [2] and it is also lower than the national target of $85 \%$ [11]. These findings are similar to those of a study conducted in Luweero which revealed that only $35.8 \%$ of the mothers had received two or more doses of IPTp [12]. Lower uptake was reported in Nigeria where only $6.5 \%$ of pregnant women had taken the recommended two doses of SP during pregnancy [13]. This low level of uptake of IPTp2 could be due to the reported regular stock-outs of SP tablets, which is one of the major barriers to the IPTp2 supply at health facilities in Uganda [14]. This finding implies that there is a need for regular supply of SP tablets in health facilities.

Bed net usage in this study was slightly higher than the national coverage of $47 \%$ [15] and higher than the $44 \%$ from the Uganda malaria indicator survey [9]. However, ITN use in this study was low compared to the national target of $85 \%$ [16]. ITN utilization was low probably because most of the mothers said that it was hard to access ITNs. Although these nets are sometimes given out at health facilities, distribution centres are far from mothers, as reported by respondents.

In this study, about half of the respondents were knowledgeable about the use of IPTp tablets. Mothers who were knowledgeable about IPTp use were 2.48 times more likely to have received at least two doses of IPTp tablets (AOR 2.48, 95 \% CI 1.53-4.02). These findings are in agreement with findings of a study conducted in Tanzania which showed that there was generally high knowledge of IPTp among pregnant women and that this high knowledge correlated well with IPTp coverage [17]. However, having knowledge alone is not enough to translate into IPTp uptake, as demonstrated in this study. Although $62.9 \%$ of the respondents knew that SP should 
Table 3 Bivariable and multivariable analysis of factors associated with IPTp2 uptake

\begin{tabular}{|c|c|c|c|c|c|}
\hline \multirow[t]{2}{*}{ Variable } & \multirow[t]{2}{*}{ Category } & \multicolumn{2}{|c|}{ IPTp2 uptake frequency (\%) } & \multirow[t]{2}{*}{ COR $(95 \% \mathrm{Cl})$} & \multirow[t]{2}{*}{ AOR $(95 \% \mathrm{Cl})$} \\
\hline & & Yes $(n=147)$ & No $(n=203)$ & & \\
\hline \multirow[t]{2}{*}{ Education } & Primary and below & $115(78.2)$ & $168(82.8)$ & $0.75(0.44-1.29)$ & \\
\hline & Above primary & $32(21.8)$ & $35(17.2)$ & 1.0 & \\
\hline \multirow[t]{2}{*}{ Marital status } & Married & $127(86.4)$ & $24(87.2)$ & $0.93(0.50-1.74)$ & \\
\hline & Not married & $20(13.6)$ & $26(12.8)$ & 1.0 & \\
\hline \multirow[t]{3}{*}{ Parity } & $<3$ & $44(29.9)$ & $69(34.0)$ & 1.0 & \\
\hline & $>5$ & $41(27.9)$ & $56(27.6)$ & $1.15(0.66-2.01)$ & \\
\hline & $3-5$ & $62(44.3)$ & $78(55.7)$ & $1.24(0.75-2.00)$ & \\
\hline \multirow[t]{2}{*}{ Employment } & Farmer & $129(87.8)$ & $177(83.7)$ & $1.39(0.75-2.58)$ & \\
\hline & Other jobs ${ }^{\mathrm{a}}$ & $18(12.2)$ & $33(16.3)$ & 1.0 & \\
\hline \multirow[t]{2}{*}{ Distance to health facility (km) } & $>5$ & $75(51.0)$ & $117(57.6)$ & $0.77(0.50-1.17)$ & \\
\hline & $<5$ & $72(49.0)$ & $86(42.4)$ & 1.0 & \\
\hline \multirow[t]{2}{*}{ Knowledgeable on IPTp use } & Yes & $51(40.5)$ & $44(19.6)$ & $2.75(1.76-4.28)^{* *}$ & $2.48(1.53-4.02)^{* *}$ \\
\hline & No & $75(59.5)$ & $180(80.4)$ & 1.0 & \\
\hline \multirow[t]{2}{*}{ Ease of access of IPTp } & Yes & $129(87.8)$ & $157(77.3)$ & $2.10(1.16-3.80)^{* *}$ & $1.71(0.89-3.30)$ \\
\hline & No & $18(12.2)$ & $46(22.7)$ & 1.0 & \\
\hline \multirow[t]{2}{*}{ Perceived susceptibility to malaria } & Yes & $135(91.8)$ & $175(86.2)$ & $1.80(0.88-3.67)$ & \\
\hline & No & $12(8.2)$ & $28(13.8)$ & 1.0 & \\
\hline \multirow[t]{2}{*}{ Served with water } & Yes & $125(85.0)$ & $115(56.7)$ & $4.35(2.56-7.40)^{* *}$ & $3.63(2.06-6.39)^{* *}$ \\
\hline & No & $22(15.0)$ & $88(43.3)$ & 1.0 & \\
\hline
\end{tabular}

COR Crude odds ratio, $A O R$ Adjusted odds ratio, $\mathrm{Cl}$ Confidence interval

${ }^{*} \mathrm{p}<0.05,{ }^{* *} \mathrm{p} \leq 0.01$

a Other jobs include civil servants, business and traditional healer

Table 4 Bivariable and multivariable analysis of factors associated with ITN use

\begin{tabular}{|c|c|c|c|c|c|}
\hline \multirow[t]{2}{*}{ Variable } & \multirow[t]{2}{*}{ Category } & \multicolumn{2}{|c|}{ ITN use frequency (\%) } & \multirow[t]{2}{*}{ COR $(95 \% \mathrm{Cl})$} & \multirow[t]{2}{*}{ AOR $(95 \% \mathrm{Cl})$} \\
\hline & & Yes $(n=205)$ & No $(n=145)$ & & \\
\hline \multirow[t]{2}{*}{ Education } & Primary and below & $156(76.1)$ & $127(87.6)$ & $0.45(0.25-0.81)^{* *}$ & $0.49(0.26-0.92)^{*}$ \\
\hline & Above primary & $49(23.9)$ & $18(12.4)$ & 1.0 & \\
\hline \multirow[t]{3}{*}{ Parity } & $<3$ & $60(29.3)$ & $53(36.6)$ & 1.0 & \\
\hline & $>5$ & $53(25.9)$ & $44(30.3)$ & $1.06(0.61-1.83)$ & $1.20(0.68-2.14)$ \\
\hline & $3-5$ & $92(44.9)$ & $48(33.1)$ & $1.69(1.02-2.81)^{*}$ & $1.71(1.01-1.29)^{*}$ \\
\hline \multirow[t]{3}{*}{ Age (years) } & $<20$ & $35(17.1)$ & $26(17.9)$ & 1.0 & \\
\hline & $>30$ & $37(18.0)$ & $36(24.8)$ & $0.76(0.39-1.51)$ & \\
\hline & $20-30$ & $133(64.9)$ & $83(57.2)$ & $1.19(0.67-2.11)$ & \\
\hline \multirow[t]{2}{*}{ Distance to health facility $(\mathrm{km})$} & $>5$ & $102(49.8)$ & $90(62.1)$ & $0.60(0.39-0.93)^{*}$ & $0.83(0.52-1.34)$ \\
\hline & $<5$ & $103(49.0)$ & $55(37.9)$ & 1.0 & \\
\hline \multirow[t]{2}{*}{ Time spent at ANC clinic (h) } & $<1$ & $26(17.7)$ & $34(16.7)$ & $1.06(0.60-1.87)$ & \\
\hline & $>1$ & $121(82.3)$ & $169(83.3)$ & 1.0 & \\
\hline \multirow[t]{2}{*}{ Ease of access of ITN } & Yes & $94(45.9)$ & $32(23.1)$ & $2.99(1.85-4.82)^{* *}$ & $2.74(1.65-4.52)^{* *}$ \\
\hline & No & $111(54.1)$ & $113(77.9)$ & 1.0 & \\
\hline
\end{tabular}

COR Crude odds ratio, AOR Adjusted odds ratio, $\mathrm{Cl}$ Confidence Interval

${ }^{*} \mathrm{p}<0.05,{ }^{* *} \mathrm{p} \leq 0.01$ 
be taken at least twice, only $42.0 \%$ actually received the recommended two doses.

The study findings also corroborated with findings of a study done in Korogwe District, northeastern Tanzania [18] which showed that although the majority recognized that SP prescribed at ANC facilities was for malaria preventive purposes, only $38.0 \%$ received two doses of SP tablets. This clearly demonstrates the knowledge gap among ANC clients and it shows that interventions that can aid in transformation of knowledge into practice are needed.

It was revealed that women who had attained post-primary education level were two times more likely to have slept under ITNs than women of pre-secondary education level. This was probably because educated women had good knowledge about the dangers of malaria, so they developed the need to protect themselves by sleeping under mosquito nets. These study findings were not in agreement with study findings in Sudan which showed that although the level of education played a major role in access to curative and preventive health services, there was no significant association between the level of education and ITN usage [19], which was consistent with study findings by [20] in Tanzania where the level of education of the household heads significantly influenced the use of nets. The study findings therefore imply that there is need to package information use of ITNs to target those mothers who lack formal education.

Mothers who had had three to five pregnancies had increased chances of sleeping under ITNs (AOR 1.69, $\mathrm{P}<0.05)$ than mothers who had had fewer than three and more than five pregnancies. This is probably because mothers who had fewer than three pregnancies had inadequate knowledge about the dangers of malaria, while those mothers with more than five pregnancies had a lower perceived need to visit ANC clinic because of their parity, and so they were less likely to go to ANC clinic, and subsequently had the reduced chance of accessing ITNs. This was in agreement with study findings in Sudan which showed that the increasing number of deliveries inversely related to the likelihood of ITN usage (AOR 0.1, $\mathrm{P}<0.05$ ), [19]. This implies that there is need to educate mothers and encourage them to attend ANC clinic and use bed nets no matter how many pregnancies they have had.

\section{Healthcare system factors associated with use of malaria control interventions}

Safe, clean water was available to the respondents for taking SP at ANC clinics. This was confirmed by $68.6 \%$ of mothers who said they were provided with free water to swallow the tablets at the clinic. Availability of water at ANC clinics encourages direct observation by nurses to ensure that women swallow the medicine, which increases the uptake of IPTp. Indeed, providing women with free clean water at ANC clinics increased the chance of women taking at least two doses of IPTp tablets by 3.63 times. This was contrary to study findings in Ghana where provision of safe water was not significantly associated with the number of SP doses received by respondents (OR 0.56, CI 0.19-1.70) [21]. These study findings therefore imply that there is need to increase access of safe water to all mothers at ANC clinics, so as to increase the level of IPTp2 uptake.

Stock-outs of SP tablets was one of the factors for low uptake of IPTp. Studies done in Kilombero, southwestern Tanzania [22] and Kibaha, eastern Tanzania [23], indicated that coverage of IPTp is influenced more by the availability of SP tablets. In a study conducted in Bungoma, eastern Kenya, SP tablets for IPTp were not always available in most health facilities and this was said to have contributed to the low uptake of IPTp2 in the district [24]. This implies that there is need to ensure a constant supply of SP tablets at health facilities to increase the coverage of IPTp2.

The study revealed that mothers who mentioned that it was easy to access ITNs were about three times more likely to have slept under an ITN the night before the survey. These study findings imply that there is need for measures to be put in place to ensure that mothers access bed nets easily since access seems to translate into use.

\section{Conclusion}

The study showed that the level of uptake of IPTp1 (at least one dose) was moderately high at $63.7 \%$ while IPTp2 (at least two doses) was relatively low at $42.0 \%$. The IPTp2 coverage was far below the national target of $85 \%$ in 2015. More than half, (58.6\%) of the respondents slept under an ITN the night before the survey. It was also shown that, about half of the respondents were knowledgeable about the use of IPTp tablets. The main factors that were associated with uptake of IPTp2 by pregnant women included education level of mothers and provision of free safe water at ANC clinics. The education level of mothers, ease of ITN access and parity of mothers were the main factors that were statistically significant for utilization of bed nets by pregnant women.

The district health team should consider intensifying health education campaigns about IPTp in the communities to improve the level of knowledge about IPTp among pregnant women. Emphasis should be put on explaining the purpose and the frequency of taking SP tablets for IPTp. Health workers should increase awareness and encourage mothers to continue sleeping under mosquito nets no matter how many pregnancies they have 
had. Health facilities should ensure that there is free safe water at ANC clinics at all times for mothers to swallow the SP tablets. The Ministry of Health should ensure that all ANC clinics are stocked with SP tablets at all times and that enough ITNs are available for distribution to health facilities.

\author{
Abbreviations \\ ANC: antenatal care; DOT: directly observed treatment; ITN: insecticide-treated \\ bed net; IPTp: intermittent preventive treatment in pregnancy; NGO: Non-gov- \\ ernment organization; PNC: postnatal care; SP: sulfadoxine-pyrimethamine; \\ UMIS: Uganda malaria indicator survey; VHT: Village health team; WHO: World \\ Health Organization.
}

\section{Authors' contributions}

$N N, M E, N J$, and EEK, participated in the inception and design of the study, NN, $M E, N J$, and BBE conducted field work, NN entered and analysed data, NN, ME and BBE wrote the first draft of the manuscript; EEK reviewed the draft of the manuscript. All authors read and approved the final manuscript.

\section{Author details}

${ }^{1}$ School of Public Health, College of Health sciences, Makerere University, P.O. Box 7072, Kampala, Uganda. ${ }^{2}$ Department of Health Policy Planning and Management, School of Public Health, Makerere University, Kampala, Uganda.

\section{Acknowledgements}

We extend our sincere appreciation to our mentor Dr. Elizabeth Ekirapa Kiracho for her guidance and technical support in implementing this research project.

\section{Competing interests}

The authors declare that they have no competing interests.

\section{Availability of data and materials}

The informed consent and ethical approval guaranteed limited access to data; the dataset has not been availed to public repositories. However, the dataset is available on request to the authors, in an anonymized form.

\section{Ethics approval and consent to participate}

Approval to conduct this study was obtained from Makerere University, School of Public Health Higher Degrees, Research and Ethics committee. Permission was also sought from Bugiri District Health Office and the local authorities of Buwunga Sub-county before conducting the study. Informed verbal consent of each individual participant was obtained before interviewing the respondents. Confidentiality was maintained for information collected from each study subject. Subjects' involvement in the study was voluntary; participants who were not willing to participate in the study and those who wished to drop out of the study at any stage were informed to do so without any restriction.

\section{Funding}

This work was funded by Medical Education for Equitable Services to All Ugandans a Medical Education Partnership Initiative Grant number 1R24TW008886 from the Office of Global AIDS Coordinator and the US Department of Health and Human Services, Health Resources and Services Administration and National Institutes of Health.

Received: 21 March 2016 Accepted: 20 June 2016

Published online: 04 July 2016

\section{References}

1. WHO. World health statistics 2010. Geneva: World Health Organization: 2010. http://www.who.int/gho/publications/world_health_statistics/ EN_WHS10_Full.pdf. Accessed 20 Oct 2015.
2. WHO. 10 facts on malaria. Geneva: World Health Organization, 2012. http://www.who.int/features/factfiles/malaria/malaria_facts/en/index2. html. Accessed 3 Aug 2015.

3. Meremikwu M, Ezedinachi E, Ehiri JE. Malaria in women and children. In: 'Maternal and Child Health: global challenges, programmes and policies'. Berlin: Springer; 2009. p. 205-23.

4. WHO. Evidence Review Group. Intermittent preventive treatment of malaria in pregnancy (IPTp) with sulfadoxine-pyrimethamine (SP). Geneva: World Health Organization; 2012. http://www.who.int/malaria/ mpac/sep2012/iptp_sp_erg_meeting_report_july2012.pdf. Accessed 15 Jun 2015.

5. USAID, President's Malaria Initiative Uganda malaria operational plan for FY 2012. http://www.pmi.gov/docs/default-source/default-documentlibrary/malaria-operational-plans/fy10/uganda_mop-fy10.pdf. Accessed 15 Aug 2015.

6. Hill J, Hoyt J, Van Ejik AM, D'Mello GL, Kuile FO, Steketee R, et al. Factors affecting the delivery, access, and use of interventions to prevent malaria in pregnancy in sub-Saharan Africa: a systematic review and meta-analysis. PLoS Med. 2013;10:e1001488.

7. Van Eijk AM, Hill J, Alegana VA, Kirui V, Gething PW, Kuile FO, et al. Coverage of malaria protection in pregnant women in sub-Saharan Africa: a synthesis and analysis of national survey data. Lancet Infect Dis. 2011;11:190-207.

8. Countdown Coverage Writing Group, Countdown to 2015 Core Group, Bryce J, et al. Countdown to 2015 for maternal, newborn, and child survival: the 2008 report on tracking coverage of interventions. Lancet. 2008:371:1247-58

9. Ministry of health Uganda. Uganda Malaria Indicator survey. Kampala, 2009. https://dhsprogram.com/pubs/pdf/MIS6/MIS6.pdf. Accessed 20 Sep 2015.

10. Uganda National Bureau of Statistics. National Population and Housing Census. Kampala, 2014. http://www.ubos.org/onlinefiles/uploads/ubos/ NPHC/NPHC\%202014\%20PROVISIONAL\%20RESULTS\%20REPORT.pdf. Accessed 15 Aug 2015

11. USAID, President's Malaria Initiative. Uganda malaria operational plan for FY 2013. https://www.pmi.gov/docs/default-source/default-documentlibrary/malaria-operational-plans/fy13/uganda_mop_fy13.pdf?sfvrsn=8, Accessed 15 Sep 2015

12. Kiwuwa MS, Mufubenga P. Use of antenatal care, maternity services, intermittent presumptive treatment and insecticide treated bed nets by pregnant women in Luwero district, Uganda. Malar J. 2008;7:44.

13. Amoran $\mathrm{OE}$, Ariba AA, lyaniwura CA. Determinants of intermittent preventive treatment of malaria during pregnancy (IPTp) utilization in a rural town in Western Nigeria. Reprod Health. 2012;9:12.

14. Thiam S, Kimotho V, Gatonga P. Why are IPTp coverage targets so elusive in sub-Saharan Africa? A systematic review of health system barriers. Malar J. 2013;12:353.

15. Uganda National Bureau of Statistics. Uganda Demographic and Health Survey. Kampala, 2011. https://dhsprogram.com/pubs/pdf/FR264/FR264 pdf. Accessed 10 Aug 2015.

16. Yeka A, Gasasira A, Mpimbaza A, Achan J, Nankabirwa J, Nsobya S, et al. Malaria in Uganda: challenges to control on the long road to elimination: I. Epidemiology and current control efforts. Acta Trop. 2012;121:184-95

17. Nyonyi JK. Factors affecting the implementation of intermittent preventive treatment of malaria in pregnancy in Dar es Salaam health facilities. 2012, e-health digital library, http://ihi.eprints.org/1659/. Accessed 15 Aug 2015.

18. Mubyazi G, Bloch P, Kamugisha M, Kitua A, ljumba J. Intermittent preventive treatment of malaria during pregnancy: a qualitative study of knowledge, attitudes and practices of district health managers, antenatal care staff and pregnant women in Korogwe District, North-Eastern Tanzania. Malar J. 2005:4:31

19. Yassin IM, Rosnah S, Osman M. Factors influencing the usage of insecticide treated mosquito nets among pregnant women. Int J Health Res. 2010;3:139-44.

20. Kinung'hi SM, Mashauri F, Mwanga JR, Nnko SE, Kaatano GM, Malima R, et al. Knowledge, attitudes and practices about malaria among communities: comparing epidemic and non-epidemic prone communities of Muleba district, North-western Tanzania. BMC Public Health. 2010;10:395. 
21. Antwi G. Factors influencing the uptake of intermittent preventive treatment of malaria in pregnancy in Bosomtwe district of Ghana. Kumasi, Ghana: Kwami Nkrumah University of Science and Technology; 2010

22. Gross K, Alba S, Schellenberg J, Kessy F, Mayumana I, Obrist B. The combined effect of determinants on coverage of intermittent preventive treatment of malaria during pregnancy in the Kilombero Valley, Tanzania. Malar J. 2011;10:140.
23. Tarimo D, Minjas J, Bygbjerg I. Perception of chloroquine efficacy and alternative treatments for uncomplicated malaria in children in a holoendemic area of Tanzania: implications for the change of treatment policy. Trop Med Int Health. 2001;6:992-7.

24. Ng'etich-Mutulei AC, Odhiambo T. Providers' knowledge of the guidelines for intermittent preventive treatment for malaria in pregnancy: evidence from Bungoma East District, Kenya. Am J Public Health Res. 2014;2:125-35

\section{Submit your next manuscript to BioMed Central and we will help you at every step:}

- We accept pre-submission inquiries

- Our selector tool helps you to find the most relevant journal

- We provide round the clock customer support

- Convenient online submission

- Thorough peer review

- Inclusion in PubMed and all major indexing services

- Maximum visibility for your research

Submit your manuscript at

www.biomedcentral com/submit 